Revista de Filosofía

Volumen 71 (2015) 93-112

\title{
TERROR, LABOR Y CONSUMO: LA SOCIEDAD DE LOS SERES SUPERFLUOS SEGÚN H. ARENDT ${ }^{1}$
}

\author{
María José López Merino² \\ Universidad de Chile \\ mjlopezmerino@gmail.com
}

\begin{abstract}
Resumen / Abstract
En el pensamiento de H. Arendt, las lecturas sobre el totalitarismo de The Origins of Totalitarianism, pueden ser leídas en paralelo a sus lecturas sobre la sociedad de masas, de la labor y el consumo en The Human Condition. Nos interesa mostrar en este artículo que se trata de lecturas convergentes, que se encuentran ligadas en la evolución del pensamiento de la autora y conservan algunas notas temáticas comunes como la preocupación por: el aislamiento, la soledad, el desarraigo y el proyecto de convertir a los seres humanos en seres superfluos.
\end{abstract}

PALABRAS CLAVE: terror, totalitarismo, campos de concentración, labor, social, sociedad de masas, consumo, seres superfluos.

TERROR, LABOR AND CONSUMPTION: THE SOCIETY OF SUPERFLUOUS BEINGS AS H. ARENDT

In the thought of H. Arendt, totalitarianism readings on The Origins of Totalitarianism, can be read in parallel to his lectures on mass society, the labor and consumption in The Human Condition. We are interested in this paper show that it is convergent readings, which are linked to the evolution of the author and thought to retain some common issues notes as concern for the isolation, loneliness, rootlessness and the project of making human beings superfluous.

KEY WORDS: Terror, Totalitarianism, Concentration Camps, Labor, Social, mass society, consumption, superfluous beings.

$1 \quad$ Este trabajo es parte del proyecto "Arendt y la Educación”, Fondo Innovación, Iniciativa Bicentenario Campus Juan Gómez Millas, Universidad de Chile. Agradezco especialmente a los integrantes del equipo de este proyecto: Camila Leyton, Pedro Mellado y Elisa Franco, ya que sin las reuniones y conversaciones con ellos, este texto no habría visto su forma definitiva. Este trabajo se inserta también en la red de investigadores creada por el proyecto: "Los residuos del mal en las sociedades postotalitarias: Respuestas desde una política democrática" (FFI2012-31635), financiado por el Ministerio de Economía y Competitividad del Gobierno de España. 2013-2015.

2 Profesora Asistente, Departamento de Filosofía, Facultad de Filosofía y Humanidades. Investigadora Fondecyt Iniciación 2008-2011 (Proyecto ${ }^{\circ}$ 11080021), Co-investigadora Fondecyt Regular 2012-2014 ( $\left.{ }^{\circ} 1110811\right)$ y Co-investigadora Fondecyt Regular 2015 (n $1140200)$. 
R⿴囗十

En una carta enviada por Mary Mc Carthy a Hannah Arendt desde París, fechada el 4 octubre de 1973, Mc Carthy -amiga, correctora y más tarde albacea de la obra de Arendt-, le cuenta de un artículo publicado en la prensa parisina y escrito por Jaques Thibau, en el que se cita The Origins of Totalitarianism para hablar del régimen militar que se está instalando luego del golpe de Estado que ha tenido lugar hace pocos días en Chile. McCarthy, reproduciendo la tesis de Thibau, reconoce que la empresa de los militares chilenos tiene al menos ambiciones totalitarias y le pregunta a Arendt si es posible pensar en este régimen militar como una nueva expresión de totalitarismo, sin dejar de opinar que posiblemente Chile [es] un país demasiado pequeño para transformarse en un Estado Totalitario (Arendt-Mc Carthy 1999, 406).

Arendt no responde a la pregunta formulada por Mc Carthy, al menos su respuesta no se recoge en la correspondencia publicada de ambas, pero muy probablemente se habría resistido a extender el término 'totalitarismo', más allá de los regímenes nazi y estalinista, tal como había quedado fijado en su difundida obra, publicada por primera vez en 1951.

En todo caso, la pregunta de Mc Carthy, nos permite poner sobre la mesa una de las cuestiones más inquietantes que quedan abiertas por el libro (The Origins of Totalitarianism): Los totalitarismos representan un peligro que sigue latente sobre el mundo contemporáneo, más allá de Europa e incluso después de la caída de los regímenes nazi y estalinista ${ }^{3}$, y no desaparece cuando estos regímenes ya han sido abolidos (Arendt 2004, p. 579). Se trata de la permanencia y la expansión planetaria de las condiciones que hicieron posible el totalitarismo, ahora en las sociedades postotalitarias. Justamente son la permanencia y expansión de estas condiciones las que nos permiten plantearnos la cuestión básica que guiará nuestro trabajo: Es posible considerar coincidencias entre la sociedad totalitaria y la moderna sociedad de masas o 'sociedad de laborantes', tal como es presentado por Arendt en The Human Condition a fines de los 50’ ¿Cuáles son estas coincidencias?

Para hacer este recorrido debemos presentar 1) la idea de terror totalitario presente en The Origins of Totalitarianism en sus descripciones centrales acerca de los campos de concentración y sus internos. Luego, debemos presentar 2) el diagnóstico del auge de lo social liderado por el animal laborans, que postula una sociedad del trabajolabor y del consumo, presente en The Human Condition, por último, 3) el diálogo y las convergencias de ambos cuerpos teóricos, en un texto específico: el epílogo Ideology and Terror, publicado en 1958 en la segunda edición de The Origins of Totalitarianism.

3 "Si es cierto que pueden hallarse elementos de totalitarismo remontándose en la Historia y analizando las implicaciones políticas de lo que habitualmente denominamos la crisis de nuestro siglo, entonces es inevitable la conclusión de que esta crisis no es una simple amenaza exterior, no simplemente el resultado de una agresiva política exterior, bien de Alemania o de Rusia, y que no desaparecerá con la muerte de Stalin más de lo que desapareció con la caída de la Alemania nazi” (Arendt 2004, 559). 


\section{El Terror: Totalitarismo y campos de concentración}

En The Origins of Totalitarianism, el totalitarismo se presenta como un sistema sin precedentes, que posee una estructura inédita (Arendt 2004, 510). Perspectiva que coincide con el modelo que durante el siglo XX será dominante en la comprensión de los totalitarismos y que en cierto sentido el pensamiento de la propia Arendt impulsará (Canovan 1992, 25). Un sistema sociopolítico nuevo, que en sus varios niveles de comprensión ${ }^{4}$ se presenta al menos como: Un sistema fundado en un partido único (Arendt 2004, 512), de extrema flexibilidad (Arendt 2004, 486), un sistema inspirado en una ideología ${ }^{5}$ que persigue no solo transformaciones en los discursos y mentalidades sino transformaciones efectivas de la sociedad, mediante la organización estatal y la generación de transformaciones sociales concretas ${ }^{6}$. Pero el rasgo central de los sistemas totalitarios para Arendt es, sin duda, que se trata de un sistema fundado en el terror. El terror es mucho más que la infusión del miedo como forma de control total sobre la sociedad y los individuos, es más bien un principio de acción política (Monstesquieu). En este sentido, y como pone de relieve Villa, para Arendt el terror es la verdadera esencia del totalitarismo y de su novedad, que en su última fase persigue la dominación total (Villa 1999, 182).

Pero para Arendt el totalitarismo además de ser un sistema político y una serie de instituciones, es un movimiento social (Canovan 1992, 29) activo y en constante cambio. Esto quiere decir, un proceso social dinámico de transformación radical, que intenta colonizar la sociedad en su conjunto cambiando las bases de la misma relación social de la comunidad, en definitiva, la relación de los seres humanos.

En tanto movimiento, el totalitarismo puede pensarse bajo la imagen de un flujo caótico, que desata una enorme violencia, que va acrecentándose y tomando proporciones inmanejables incluso para los propios líderes del movimiento. Este poder de destrucción, antes incluso que la construcción de una utopía, es el que mantiene el dinamismo del movimiento (Canovan 1992, 27). Desde la propia ideología, en tanto discurso justificativo, el propio totalitarismo se ve a sí mismo como el simple ejecutor

4 Para una visión completa de las condiciones de los sistemas totalitarios ver Arendt (2004 y 1994a), The Origins of the totalitarianism. Especialmente la tercera parte: Totalitarismo, pp. 385-580. También, Arendt (2005), Ensayos de Comprensión: 1930-1954, pp. 371-434.

5 “...las ideologías son sistemas de explicación de la vida y del mundo que pretenden explicarlo todo, el pasado y el futuro, sin necesidad de ulterior contrastación con la experiencia efectiva" (Arendt 2005, 421).

6 "Lo que es nuevo en la propaganda ideológica de los movimiento totalitarios, antes incluso de la toma de poder, es la transformación directa, a través de los instrumentos de organización totalitaria, del contenido ideológico a la realidad viva. Lejos de organizar personas que resultaba que creían en el racismo, el movimiento nazi las organizó de acuerdo con criterios raciales objetivos, de modo que la ideología racial dejó de ser asunto de mera opinión o de argumentación, incluso de fanatismo y constituía la realidad efectiva viva, primero del movimiento nazi y luego de la Alemania nazi” (Arendt 2005, 422). 
de la sentencia de destrucción que dicta la ley de la Naturaleza o de la Historia ${ }^{7}$, sobre individuos y pueblos enteros (Canovan 1992, 28).

En este sentido, el terror totalitario para Arendt requiere de una capacidad de destrucción, que no se explica por el puro anhelo de poder, ni por el incentivo personal, ni por los deseo de expansión imperialista de un pueblo, no parece tener causas utilitarias. Se trata más bien de una agresividad difícilmente explicable desde causas racionales. Lo que constata Arendt es que el terror funciona bajo la creencia propiamente moderna de que todo es posible, postulada por gran parte de la filosofía moderna y realizada por la técnica. Pero esta creencia es realizada por el totalitarismo únicamente bajo la modalidad: todo puede ser destruido (Arendt 2004, 556).

Así, el movimiento totalitario se identifica con un cierto caos estructural, que constantemente se reorganiza en torno a sus dos instituciones centrales: la policía secreta y los campos de concentración.

La centralidad que da Arendt a la experiencia del holocausto en su comprensión del totalitarismo (Canovan 1992, 26), expresa no solo el intento de comprender el sistema totalitario nazi desde la experiencia de los campos de concentración, sino el esfuerzo de asumir la cuestión de los campos de concentración como uno de los fenómenos políticos centrales, haciendo ver que se trata de un verdadero punto de partida para la comprensión política del mundo contemporáneo. En este sentido, cuando Arendt investiga sobre los campos, transforma su propia percepción del totalitarismo y logra darle a su trabajo sobre este tema una orientación definitiva (Bernstein 2002, 98). Al mismo tiempo, nos entrega una de las primeras y más completas descripciones de estos lugares, su funcionamiento y la experiencia de los internos ${ }^{8}$.

Para la autora alemana, los campos de concentración administrados por la policía secreta tienen como función central la de ser laboratorios de la dominación total (Arendt 2004 , p. 533). Se trata de los campos organizados para generar el mayor tormento posible entre los internos (Arendt 2004, 541) y para funcionar de guía social (Arendt 2004, 533). Se constituyen en un verdadero modelo: el sistema totalitario perfecto sería aquel que pudiera convertir a la sociedad completa en un campo de concentración.

Para realizar esta función de dominación, se hace necesario: el completo y más estricto aislamiento del exterior (Arendt 2004, 533) para que se genere un abismo entre el mundo de los vivos y el de los vivos-muertos (uno de los nombre que Arendt da a los internos) $)^{9}$. Esto tiene como resultado el hecho de que mantiene a los campos en un

7 “...Su propósito ultimo no es la tranquilidad de su propio régimen, sino la imitación, en el caso de Hitler, o la interpretación en el caso de Stalin, de las leyes de la Naturaleza o la Historia" (Arendt 2005, 416).

8 Las principales fuentes que toma Arendt es su descripción de los campos son las fuentes testimoniales de los sobrevivientes, principalmente los libros de Rousset, Bettelheim, la compilación de testimonios de Tallin. Ver Arendt 2004, 537 y ss.

9 Los internos son llamados por Arendt de varias manera: muertos vivos (Arendt 2004, 538) o testigos oculares (Arendt 2004, 536-537), también los nombra como desaparecidos 
ámbito más allá de lo real (Arendt 2004, 536). Lugares que al constituirse al margen de las leyes y de las normas mínimas de legalidad o convivencia social, adquieren un cierto grado de irrealidad como al margen de la vida y la muerte ${ }^{10}$.

También se trata de lugares que requieren, según Arendt un sistema organizativo interno que aísla a los grupos y a los mismos individuos de manera de conseguir romper los lazos de solidaridad entre ellos (Arendt 2004, 538), y así, mantener a los internos en la apatía, procurando organizar desde este aislamiento, no solo la muerte y el padecimiento, sino también el olvido (Arendt 2004, 548). Para este efecto, se busca hacer desaparecer a las víctimas y los vestigios mismos del crimen cometido, intentando hacer como si esas personas en realidad nunca hubieran existido ${ }^{11}$.

Este intento de borrar todo gesto de individualidad, incluida la muerte individual, es en realidad el resultado de un largo proceso que se inicia en realidad mucho antes que los internos pisen el campo. Comienza con la etapa que busca matar a la persona jurídica: esto significa despojar de la ciudadanía y por lo tanto de sus derechos jurídicos y capacidad para ser protegido por un Estado a un grupo de la población. En el proceso nazi esto ocurrió con distintos grupos que progresivamente fueron dejados fuera de la protección de la ley y de esta manera quedaban en una situación de vulnerabilidad (Arendt 2004, 543). Continúa con el intento de matar a la persona moral: a través del aislamiento tanto externo como interno, se instituyen en los campos una serie de estrategias dirigidas a privar a los individuos de su dignidad más básica (torturas, humillaciones, obligación de las víctimas de participar en las muertes de otros, etc.). En su última fase, la destrucción se orienta a matar a la individualidad: se trata de la última etapa, en la que bajo distintos métodos se busca despojar a los individuos de toda espontaneidad y singularidad (Arendt 2004, 550), logrando como resultado la aparición de un hombre inanimado (Arendt 2004, 536). De un muerto-vivo (Arendt 2004, 532) o de un animal completamente pervertido (Villa 29). Para terminar en una muerte completamente anónima, privada de la individualidad, del dolor de los otros y del recuerdo ${ }^{12}$.

(Arendt 2004, 538) o como individuos sustituibles por otro, por cualquiera (Arendt 2004, 540). En el caso de aquellos que no vivieron los campos pero que sufrieron su impacto y pueden seguir hablando de ellos, Arendt habla de los conmovidos por los hechos (Arendt 2004, 537).

10 "Su horror nunca puede ser abarcado completamente por la imaginación por la simple razón de que permanecen al margen de la vida y de la muerte. Nunca puede ser totalmente descrito por la razón del superviviente que retorna al mundo de los vivos, lo que le hace imposible creer por completo en sus propias experiencias pasadas" (Arendt 2004, 539).

11 "El asesino deja un cadáver tras de sí y no pretende que su víctima no haya existido nunca; si borra todos los rastros son los de su propia identidad, y no los del recuerdo y del dolor de las personas que amaban a la víctima; destruye una vida, pero no destruye el hecho mismo de la existencia" (Arendt 2004, 538).

12 "En los países totalitarios todos los lugares de detención dirigidos por la Policía quedan convertidos en verdaderos pozos del olvido en los que las personas caen por accidente y 
Como consecuencia de esta última etapa y mucho antes de la llegada de la muerte física, el totalitarismo cumple con un doble objetivo: la anulación de la individualidad y el quiebre de la interrelación con otros. Así, logra erradicar ...bajo condiciones cientificamente controladas, la espontaneidad (Arendt 2004, 533), y con ello, la capacidad de los hombre de actuar juntos y crear poder (Arendt 2005, 406). En esto consiste el fin último de los campos, o como lo llama la autora, el mal radical que el totalitarismo realiza: hacer a los hombres superfluos. Cuestión que, como muestra Bernstein (2002, pp. 290-314), constituye un hilo conductor para abordar la cuestión del mal en la obra de Arendt.

Dentro de la descripción que realiza Arendt, quienes detentan el poder de administrar los campos de concentración son los miembros de la policía secreta, institución que se vuelve depositaria del poder ejecutivo real ${ }^{13}$. Se trata de un grupo que funciona como ...una sociedad secreta a plena luz del día (Arendt 2004, 506), constituyéndose en el segmento privilegiado del sistema, la verdadera elite que liderará los cambios y las acciones fundamentales del régimen ${ }^{14}$. Se trata de un grupo de privilegiados al interior del sistema, una elite dentro de otra elite (partido) que, a pesar de la apariencia de cumplir un rol subalterno al gobierno y al Estado, en realidad dirigen indirectamente el gobierno y el Estado, están llamados a liderar los cambios en curso ${ }^{15}$.

Mediante su acción, cada vez más amplia e indiscriminada, las policías secretas logran la universalización del terror a toda la sociedad (Arendt 2005, 418). Existe así, un momento en el que todos los individuos pueden ser potenciales víctimas, independiente de lo que piensen o hagan, porque a esas alturas la actuación de la policía secreta no es predecible ${ }^{16}$. Al mismo tiempo, todos los ciudadanos pueden ser potenciales victimarios, en tanto se promueve la colaboración directa e indirecta con el régimen y se propone una lógica de amigos y enemigos de la que nadie puede sustraerse.

El principal secreto que guarda la policía secreta es justamente toda la información relacionada con los campos de concentración (Arendt 2004, 531). Este secreto resulta central en la mantención del propio poder: mientras mantengan a resguardo esta información y, por tanto, se comporten efectivamente como una sociedad secreta

sin dejar tras de sí los rastros ordinarios de su antigua existencia como un cuerpo y una tumba" (Arendt 2004, 529).

13 "En los Estados totalitarios, ni el Ejercito ni la Iglesia ni la burocracia estuvieron nunca en una posición de ejercer el poder o de restringirlo; todo poder ejecutivo está en manos de la policía secreta" (Arendt 2004, 417).

14 Arendt sugiere que Hitler a pesar de la evidencia de ciudades bombardeadas y el ejército diezmado, solo consideró la guerra perdida cuando perdió la confianza en las SS (Arendt 2004, 511).

15 Lo nazis creían en: "El amanecer de la raza de señores, (pero los señores) no eran los alemanes, sino las SS" (Arendt 2004, 504).

16 "Sólo en su fase última y completamente totalitaria quedaban abandonados los conceptos del enemigo objetivo y del delito lógicamente posible, elegidas las victimas completamente al azar y, sin llegar a ser acusadas, declaradas incapaces de vivir" (Arendt 2004, 527). 
(Arendt 2004, 530), su poder estará a resguardo. Generalmente esta sociedad secreta seguirá operando, más allá del término del régimen totalitario, estableciendo pactos de silencio que se mantienen en la mayoría de los casos a pesar de que las condiciones de estas elites cambien radicalmente. Esto dificulta el conocimiento y la circulación de información acerca de los campos, que mientras dura el régimen, se queda en el ámbito de lo subjetivo: la información que se mantiene como ...incomprobable e inviable respecto de los lugares de los muertos vivos (Arendt 2004, 532).

\section{El 'auge de lo social'y la 'sociedad de laborantes'}

En su obra The Human Condition, siete años después de la primera edición de The Origins of Totalitarianism, la filósofa presenta un diagnóstico de la sociedad moderna, profundamente ligado a ciertas disposiciones sociales orientadas por aislamiento, la soledad, la falta de espontaneidad, cuyo resultado es la idea de un sujeto sin atributos. Esto no significa entender la sociedad moderna como totalitaria, ni Arendt ni la mayoría de los pensadores que hicieron ese tránsito teórico, del totalitarismo a la sociedad posttotalitaria en el siglo XX, plantean una relación tan directa entre sociedad totalitaria y sociedad de masas ${ }^{17}$. Se trata más bien de la identificación de disposiciones protototalitarias de la modernidad, previas a la aparición de los sistemas totalitarios y que perviven latentes en las sociedades postotalitarias. Maneras de pensar, contenidos teóricos y disposiciones prácticas, políticas y técnicas, que harán posible la instalación de la sociedad totalitaria en el mundo contemporáneo, y que persisten como condiciones permanentes una vez que han caído estos regímenes, haciendo real el peligro de que vuelvan a surgir.

En términos generales, Arendt llama a este diagnóstico, el auge de lo social (Arendt 1998, II, 6, 38), fenómeno que tiene su aparición junto con el surgimiento mismo de la modernidad ${ }^{18}$ y sus raíces en los orígenes de la cultura y el pensamiento occidentales. Se trata de un fenómeno cultural extenso según Arendt y no resulta fácil distinguir su real y específico significado (Sánchez 2003, 275). En verdad, el auge de lo social no describe un único fenómeno, sino que se refiere indistintamente a una constelación de problemas y perspectivas de análisis de la cuestión moderna (Pitkin 1998). A nuestro juicio, es necesario diferenciar, al menos analíticamente, tres sentidos básicos de lo social:

17 Podemos pensar en un itinerario paralelo entre Arendt y algunos pensadores de la Escuela de Frankfurt en este punto. A pesar de las enormes diferencias entre Arendt y autores como Adorno o Marcuse, coinciden en un tránsito desde el pensamiento acerca del totalitarismo y el pensamiento y la crítica de la sociedad de masas y la sociedad de consumo.

18 Ver 6. El auge de lo social, en y VI 35 y ss. La Vita Activa y la época moderna, en La condición humana (Arendt 1993).También, II Imperialismo. Cap. 9, El declive del Estado Nación y el fin de los Derechos del Hombre (Arendt 2004). 
- En primer lugar, lo social se define por oposición a lo político, que tiene lugar en el espacio público, y es posible mediante la acción colectiva, en el que actuamos y hablamos con otros (Arendt 1993, 199-212). Hay que tener en cuenta, como señala Sánchez, que la oposición más radical en el pensamiento de Arendt no es la de lo público y lo privado, sino justamente la que se establece entre lo político y lo social ${ }^{19}$. Este concepto de lo social le trae a la autora un gran número de críticas $^{20}$, pero lo importante para nosotros es que lo social refiere aquí a la crisis de lo político específicamente moderna, vinculada a la pérdida de prioridad de lo público-político frente a lo administrativo-estratégico. Junto con ello, a la pérdida de los espacios asociativos que hacen posible la libertad política, es decir, a la despolitización, que está en la base de la comprensión y administración moderna de lo político.

- Pero también, en segundo lugar, lo social involucra directamente una crítica al surgimiento de las relaciones de mercado, al capitalismo y al enfoque de la moderna economía y su prioridad sobre la institucionalidad y el quehacer políticos. Prioridad que se traduce en que la 'cuestión social' pasa a primer plano de la discusión social. La política retrocede frente al espacio de la satisfacción de las necesidades que es entendido y satisfecho por la economía, según Arendt.

- En tercer lugar, y ya desde el interior de la comprensión capitalista de la moderna economía: lo social refiere específicamente a la sociedad de la labor y del consumo, bajo el esquema de una sociedad de masas. Tal como muestra Arendt en el epílogo de The Origins, la piedra angular de este modo de organización social específicamente moderno, es la instauración de una forma de trabajo en el que el homo faber se despoja de sus capacidades creadoras y queda supeditado a un programa de producción para una sociedad de consumo. En este esquema y horizonte de comprensión, el trabajo se desdibuja en su sentido originario y el trabajador queda igualado en su actividad, a la actividad de sobrevivencia del animals laborans.

\subsection{Animals laborans y homo faber: laborar y trabajar}

La distinción clave para entender este último significado del 'auge de lo social': la imposición de una sociedad de labor y consumo, y la transformación de la idea de trabajo en ella supuesta, está en la distinción con la que se inicia el capítulo III de The Human Condition, entre labor (labor) y trabajo (work) y que le permite a la autora elaborar en ese y los siguientes capítulos (especialmente IV) una radical crítica a la idea moderna

19 Sánchez ofrece un excelente cuadro resumen de las diferencias entre lo político y lo social en Arendt; ver Sánchez 2003, p. 280.

20 Críticas centradas en la dificultad de distinguir entre lo social y lo político, y en la inaplicabilidad de su concepción de lo político (Habermas 1984, p. 215). 
de trabajo. Como la propia autora reconoce, se trata de una distinción poco usual en el pensamiento político especialmente el moderno (Arendt 1993, 98), que en realidad ha tendido a confundir ambas actividades prácticas.

Como en otros casos, Arendt comienza su análisis reparando en la evolución de las lenguas modernas: éstas muestran una tendencia al desdibujamiento del concepto de 'trabajo' y su oposición al de 'labor', a pesar de lo cual la distinción se puede reconocer todavía en algunas lenguas ${ }^{21}$. Se trata de una sobreposición del concepto de 'labor' al de 'trabajo' que tiene una especial significación en la historia conceptual que Arendt está presentando: se trata de la confusión moderna que ha tendido a encubrir la fisonomía propia del trabajo (work) como actividad práctica. Originalmente, el trabajo es la actividad de fabricación del homo faber, que a la luz de ciertas ideas y planes, interviene el mundo material, creando objetos que ...garantizan la permanencia y durabilidad, sin las que no sería posible el mundo (Arendt 1993, 107). El tiempo del trabajo es lineal, y se identifica con la producción de objetos. Su 'lógica' o racionalidad es la de los medios/fines: se fija un objetivo de creación y se hace de los medios para llegar a cumplir con ese objetivo. La labor que realiza el animal laborans en cambio, es la actividad práctica necesaria para el mantenimiento de la vida, en su sentido más elemental (Arendt 1993, 109). Su tiempo es siempre cíclico, porque una vez que termina de 'mantener' la vida, debe comenzar de nuevo, y su lógica es la repetición constante de este ciclo de la sobrevivencia: se labora para consumir lo necesario para la vida y una vez que se consume, el ciclo comienza otra vez (Arendt 1993, 108).

Mientras los productos del trabajo se usan, los productos de la labor se consumen. Mientras la producción (poiesis) o el trabajo (work) van unidos al placer de crear, haciendo uso de la imaginación, la actividad laborante va unida inevitablemente a la dureza del quehacer de 'mantener la vida' (Arendt 1993, 111) y no tiene más sentido, que la generación de las condiciones para la vida en su sentido más básico: la sobrevivencia.

Según el diagnóstico de Arendt, las condiciones de la moderna comprensión del trabajo surgen de una supremacía del animal laborans, que realiza prácticamente el trabajo como labor, y la eleva a la actividad práctica por excelencia, identificándola finalmente con la praxis o acción, la que ha perdido su sentido original (como capacidad de iniciar con otros). Debido a esto, ocurre una transformación completa de la comprensión de las actividades prácticas (labor, work, action). Arendt presenta esta inversión, siguiendo la pista de al menos tres de los pensadores centrales de la modernidad que habrían formulado en términos teóricos las etapas decisivas de este proceso social de transformación: El repentino y espectacular ascenso de la labor desde la más humilde y despreciada

21 Frente a la distinción todavía vigente en el inglés labor-work, las distinciones ya no muy usadas en alemán Arbeit- Werk y francés labourer-travailler, ver Arendt 1993, 142, nota 5. Es especialmente curiosa la coincidencia en este punto de Arendt con Engels, quien al final del primer capítulo de la segunda edición inglesa de El Capital anota una reflexión muy similar, haciendo ver como la distinción en inglés entre labor/work, no es posible encontrarla ya en alemán. 
posición al rango más elevado, a la más estimada de todas las actividades humanas, comenzó cuando Locke descubrió que la labor es la fuente de toda propiedad. Siguió su curso cuando Adam Smith afirmó que la labor era la fuente de toda riqueza y alcanzó su punto culminante en el 'sistema de labor' de Marx, donde ésta pasó a ser la fuente de toda productividad y expresión de la misma humanidad del hombre (Arendt 1993, 113). Se trata de tres momentos en la comprensión moderna del trabajo-labor que son fundamentales para forjar la concepción moderna de trabajo y de mundo práctico de la sociedad capitalista que esta noción abre. El trabajo como poder de apropiación y fuente de legitimidad para la propiedad privada (Locke). El trabajo que se puede acumular como origen de la riqueza (Smith), y en definitiva del capital, y por último, el 'sistema del trabajo' (System der Arbeit) que convierte la fuerza de trabajo en mercancía (Marx). En sentido arendtiano, más bien 'sistema de labor-trabajo', que hace posibles la producción capitalista y la acumulación, resignificando la esfera práctica completa que ya no es entendida política, sino económicamente.

En el centro de la comprensión marxiana del trabajo para Arendt, está el descubrimiento de la productividad entendida como 'fuerza de trabajo' (Arbeitskraft) que hace posible pensar la capacidad productiva del trabajo-labor, en tanto poder que más allá de la sobrevivencia puede generar un superavit (plusvalía) 22 . Es esto lo que hace del trabajo humano una fuerza económica, la fuente de la acumulación y el origen del capital que no es más que 'trabajo acumulado'. En este sentido: Debido a que lo que explica la productividad de la labor no está en sí misma, sino el superávit que ella produce, en 'la fuerza del trabajo' (Arbeitskraft), la introducción de este término por Marx constituyó, como Engels señaló acertadamente, el elemento más original y revolucionario de todo su sistema (Arendt 1993, 103).

La idea de que existe una 'fuerza del trabajo-labor', que es medible, acumulable, capaz de generar excedente, expropiable, transable en un 'mercado de trabajo', y que es la fuerza que hace andar el sistema capitalista, es una concepción lo suficientemente abstracta para servir a la comprensión de las nuevas relaciones de producción del nuevo sistema y convertir al trabajo-labor en la moneda de cambio de ese sistema. Al mismo tiempo, esta idea supone un dinamismo productivo nuevo, ya no inspirado en la producción de objetos y su lógica poiética, que Arendt ha puesto de relieve con el concepto de trabajo (work), sino en el excedente dinámico de un sistema de reproducción que sigue siendo un sistema de sobrevivencia, aunque su producción genere superávit, o mejor aún, es un sistema de la sobrevivencia ahora sin límites ${ }^{23}$.

22 Según nuestra autora: "Dicha productividad no se basa en los productos de la labor, sino justamente en el 'poder', que es sobre todo un poder transformador, cuya fuerza no queda agotada cuando ha producido los medios para su propia subsistencia y supervivencia, sino que es capaz de producir un 'superávit', producir más de los necesario para su propia 'reproducción'” (Arendt 1993, 103).

23 En este sentido, se trata de un sistema que “....se interesa por los medios de su propia reproducción, puesto que su poder no se agota una vez asegurada su propia reproducción, 
Parece bastante evidente en estas críticas al trabajo-labor, la resonancia de las lecturas de Marx que la autora está realizando en esta época, y que son parte de la discusión teórica que da origen a la redacción de The Human Condition ${ }^{24}$. Cercana resulta en este punto la crítica a la noción de trabajo alienado del joven $\mathrm{Marx}^{25}$, aunque Arendt en The Human Condition, cita y refiere a la noción de trabajo de El Capital ${ }^{26}$. No es tema de este artículo discutir estas lecturas, que han sido muy criticadas, aunque no suficientemente analizadas ${ }^{27}$. Solo nos interesa rescatar la centralidad que Arendt asigna a la experiencia moderna del trabajo para esclarecer algunos de los aspectos de su diagnóstico del auge de lo social y la crítica que en esas reflexiones se desliza a la economía política del Marx maduro: al trasfondo mecanicista y naturalista de esta visión del sistema de la labor cómo fuerza de la labor-trabajo. En este sentido, la noción de 'fuerza de trabajo' (Arbeitskraft) permite describir el modelo de la producción capitalista y especialmente el trabajo alienado, pero, al mismo tiempo, parece razonable preguntarse si el mismo concepto de trabajo, reducido a 'fuerza de trabajo' (Arbeitskraft) no está demasiado instalado en el horizonte capitalista como para convertirse en el comienzo de una comprensión crítica emancipadora que permitirá criticar a fondo las bases epistémicas y finalmente ontológicas de ese sistema de dominación que denuncia ${ }^{28}$.

Esta crítica toma su dimensión al interior de la obra de Arendt, si recordamos el concepto clave en la noción de política de Arendt, que es el concepto de poder (power), entendido como acción concertada. Este concepto de poder puede ser pensado en gran medida en oposición a la noción de 'fuerza de trabajo'. El poder en el sentido arendtiano es justamente un poder plural que surge con otros y no individualmente (no es fuerza), no se vincula a las bases físicas o biológicas y menos a su superávit. Se trata de un poder que no se puede medir, es inexpropiable, intransable, no se puede traspasar ni acumular, el poder no se puede gobernar ni dominar (Arendt 1993, 222 y ss), es, como

puede usarse para la reproducción de más de un proceso de vida, si bien no 'produce' más que vida" (Arendt 1993, 103).

24 Como concluye Young-Bruhel: "En el espacio de cuatro años, de 1958 a 1962, Hannah Arendt publicó tres libros, The Human Condition (1998), Between Past and Future (2006b) y On Revolution (2006a), todos los cuales salieron de sus estudios para el proyectado y nunca escrito libro sobre el marxismo" (Young-Bruhel 1993, 359).

25 Podríamos ver algunos puntos de contacto entre la visión de Arendt y del joven Marx, específicamente a partir de la noción de trabajo alienado de los Manuscritos del 44', de este último (Marx 2000).

26 Ver Marx (2011), El Capital, Libro 1, Sección primera. Mercancía y dinero.

27 Para una visión general de la lectura que Arendt hace de Marx, ver al menos Parekh en Hill (1979), Tassin (1999), Villa (1999), Forti (1996). Para una lectura centrada en aspectos específicos de la lectura del trabajo: Schutting (1962), Bakan y Major, en Hill (1979), Ring (1989), Holman (2011).

28 La verdadera crítica a la dominación y al trabajo alienado debería desde esta perspectiva convertirse también en una crítica epistémica y ontológica a las formas de comprensión del 'materialismo dialéctico'. En una línea, congruente con la de Arendt, ver Henry (2011). 
ya hemos dicho en otra parte, un poder salvaje (López 2010, 647), lo absolutamente otro de la 'fuerza de trabajo' como categoría económica.

\subsection{Trabajo-labor y consumo}

En otro aspecto fundamental de su crítica a la noción moderna de trabajo-labor, Arendt se enfoca en el hecho de que la idea de trabajo-labor moderna lleva aparejada la actividad del consumo. En su sentido específicamente moderno, laborar es trabajar para el consumo como sobrevivencia. En este sentido, aclara la filósofa: Cuando Marx definió la labor como 'metabolismo del hombre con la naturaleza', (...) indicaba con claridad que 'hablaba fisiológicamente' y que labor y consumo no son más que dos etapas del siempre repetido cíclico de la vida biológica'. Este ciclo requiere que lo sustente el consumo, y la actividad que proporciona los medios de consumo es la labor (Arendt 1993, 112). El trabajo-labor es el quehacer para el consumo y es inseparable de éste. Es necesario para el mantenimiento de la vida humana, actividad antiguamente relegada a la oscuridad de lo privado, pero luego con el moderno sistema de producción capitalista, convertida en el centro de la actividad pública. Con la modernidad, esta actividad de consumo que acompaña la labor-trabajo queda inserta en un sistema de producción para el consumo (se comienza a) ...tratar todos los objetos usados como si fueran bienes de consumo (Arendt 1993, 134).

Así se inicia el ciclo de la labor-consumo como ciclo interminable, completamente necesario para que el moderno sistema de producción capitalista funcione y se desarrolle. Sin consumo ilimitado no hay producción ilimitada, ni expansión del capital ${ }^{29}$. Esto lleva aparejado el hecho de que el uso y los objetos de uso pierdan su valor y se convierten en bienes que quedan también disminuidos en su objetividad, en su capacidad de permanencia. Debemos, nos advierte la autora: ....consumir, devorar, por decirlo así, nuestras casa, muebles y coches, como si fueran las 'buenas cosas'de la naturaleza que se estropean inútilmente si no se llevan con la máxima rapidez al interminable ciclo del metabolismo del hombre con la naturaleza. Es como si hubiéramos derribado las diferenciadas fronteras que protegían al mundo, al artificio humano, de la naturaleza, tanto el biológico proceso que persigue su curso en su mismo centro como los naturales proceso cíclicos que lo rodean, entregándoles la siempre amenazada estabilidad de su mundo humano (Arendt 1993, 135). De esta manera, es el artificio humano, en lo que tiene de trabajo imaginativo y actividad creadora y protectora del mundo, el que

Nuevamente aquí las posibles relaciones con el pensamiento de Marx resultan bastante evidentes. Sobre todo con las descripciones de la sección séptima: El proceso de acumulación del capital, y sección primera en torno a las nociones de valor de uso y valor de cambio. Libro 1 de El Capital. De Arendt ver: Imperialismo, Cap. V La emancipación política de la burguesía, en Los orígenes del Totalitarismo (2004). 
ha perdido su sentido ${ }^{30}$. Dejándonos en cierto sentido desprotegidos, ante la futilidad de una actividad laborante, que repite incansablemente el ciclo de la sobrevivencia.

\subsection{Trabajo-labor y propiedad}

Otra transformación definitiva para Arendt, de la moderna economía capitalista de la mano de su comprensión del trabajo, es la que sufre la propiedad privada; que pierde su sentido de lugar poseído privadamente dentro del mundo sea capaz de soportar el implacable proceso del crecimiento de la riqueza (Arendt 1993, 123). Según Arendt, el tema central de la economía moderna ya no es la propiedad privada, como lugar de protección de la luz pública, sino la riqueza y su acumulación sin límites ${ }^{31}$. Se trata de la absorción del proceso de reproducción de la vida individual por el de la vida de la especie que comienza a ser el verdadero protagonista de este proceso de acumulación ahora infinito en su 'vida' y en su necesidad de 'reproducción' (Arendt 1993, 133).

El 'auge de lo social' con la instalación plena del animal laborans de la especie, la 'humanidad socializada' no trae, según Arendt, ninguna forma de libertad. Muy por el contrario, esta 'humanidad socializada' coincide con una sociedad contemporánea de esclavos que ha perdido el último horizonte de su arraigo, la posibilidad del mundo: Una sociedad de masas de trabajadores, tal como Marx la tenía en mente cuando hablaba de 'humanidad socializada', está compuesta de especímenes no mundanos de la especie de la humanidad, trátese de esclavos domésticos llevados a su situación por la violencia de otros o de hombres libres que realizan sus funciones de manera voluntaria. Esta no-mundaneidad del animal laborans es diferente por completo de la activa huida de la publicidad del mundo, inherente a la actividad de las 'buenas obras'. El animal laborans no huye del mundo, sino que es expulsado de él en cuanto que está encerrado en lo privado de su propio cuerpo, atrapado en el cumplimiento de necesidades que nadie puede compartir y que nadie puede comunicar plenamente (Arendt 1993, 128).

Este oscuro diagnóstico culmina en esta nueva forma de organización social que es la 'sociedad de masas'. Gobernada por el animal laborans como animal sin mundo, sin arraigo que dé realidad a su condición humana (Arendt 1993, 141), afanado en las únicas actividades de laborar y consumir, y que ha terminado también con la posibilidad del espacio público como espacio político. En este sentido, mientras el animal laborans ocupe el espacio de la esfera pública, esta esfera como tal, no será posible ${ }^{32}$.

30 "Los ideales del homo faber, el fabricador del mundo, que son la permanencia, estabilidad y carácter durable, se han sacrificado a la abundancia, ideal del animal laborans" (Arendt 1993, 135).

31 “...sin estar trabado por las limitaciones que impone el período de la vida individual y la propiedad poseída individualmente" (Arendt 1993, 125).

32 “...al animal laborans se le permitió ocupar la esfera pública; y sin embargo, mientras el animal laborans siga en posesión de dicha esfera, no puede haber auténtica esfera pública, 
En definitiva, la negación radical de la experiencia de la libertad es lo que el ascenso de lo social supone para los laborantes-consumidores, y nada tiene que ver con el desarrollo de las condiciones materiales, las condiciones tecnológicas o el aumento de las comodidades de una sociedad. Muy por el contrario, en una línea que nos acerca bastante a la unidimensionalidad descrita por Marcuse (2010), o del imperio de Negri (2002), mientras más fácil y eficiente sea este proceso de labor-consumo, posiblemente las condiciones de dominación, la imposibilidad de la acción, la dificultades para hablar y actuar ante y con otros, la ocurrencia de lo común y de lo público, todas condiciones de la libertad política como la entiende la autora, son cada vez más escasas. El peligro radica en que tal sociedad, deslumbrada por la abundancia de su creciente fertilidad $y$ atrapada en el suave funcionamiento de su proceso interminable, no sea capaz de reconocer su propia futilidad, la futilidad de una vida que 'no se fija o realiza en una circunstancia permanente que perdura una vez transcurrida la (su) labor (Arendt 1993, 142).

\section{Terror, labor y consumo}

La relación de estos dos cuerpos de ideas y críticas, la primera centrada en el totalitarismo y el largo proceso de experimentación y degradación que ocurre a los internos en los campos de concentración y que culmina con la aparición de los muertos-vivos, que son los propios internos. La segunda, centrada en la idea de trabajo-labor y el consumo en la 'sociedad de laborantes' que es también la de los consumidores, como animales sin mundo es lo que ahora nos queda por establecer. Para ello es necesario acercarnos a un texto clave en la evolución del pensamiento de Arendt y que hace de transición en su biografía intelectual: Se trata del epílogo Ideology and Terror, de The Origins of Totalitarianism, escrito algunos años después de la publicación de la primera edición del libro en 1951 y agregado recién en la segunda edición de 1958, año de la publicación de The Human Condition ${ }^{33}$. Este epílogo puede ser pensado como un texto puente entre dos períodos del pensamiento de la autora caracterizados por estas dos grandes obras. Intenta dar cierre al libro sobre el totalitarismo, volviendo sobre los temas centrales del terror totalitario; pero al mismo tiempo ya tiene a la vista el nuevo objeto de estudio en el que la filósofa está empeñada: la moderna sociedad de masas, entendida como 'sociedad de laborantes'. Es así como el texto transita en varias ocasiones de un tema a otro (Ver Arendt 2004, 554, 572 y ss).

sino solo actividades privadas abiertamente manifestadas. El resultado es lo que llamamos con eufemismo cultura de masas" (Arendt 1993, 140).

33 El año 1957, un año antes de la publicación de este epílogo, en la nueva edición de The Origins of Totalitarianism y de la publicación de The Human Condition, Arendt dicta la conferencia "Labor Work, Action" en la Universidad de Chicago, conferencia que es la primera versión de la descripción de las tres actividades; labor, trabajo y acción, que componen de The Human Condition. 
Uno de los primeros puntos de contacto entre ambos diagnósticos en el texto es la noción de aislamiento. La sociedad del campo de concentración, ya lo hemos dicho, es una sociedad que no solo aísla a los internos del campo con el exterior, sino que crea un aislamiento entre los internos, el que resulta completamente necesario para el desarrollo del proceso de degradación en curso (Arendt 2004, 547 y ss). Como veíamos en el primer apartado, el resultado del terror totalitario, aunque comienza a mostrarse mucho antes, se consuma al interior del campo con el radical aislamiento de los sujetos y el uso de técnicas orientadas a la destrucción de la persona (Arendt 2004, 572). Este aislamiento curiosamente está alimentado también por un esfuerzo de hacer perder el espacio que nos separa de los demás. Como se nos aclara en el epílogo: Presionando a los hombres unos contra otros, el terror total destruye el espacio entre ellos (Arendt 2004, 565). Espacio que hace posible la aparición de la distinción, la unicidad (uniqueness) de cada uno que se destaca en el espacio de comparecencia ante los otros (Arendt 1993, $220 \mathrm{ss}$ ), todos aspectos fundamentales para la aparición de la identidad. El aislamiento así pensado separa a los individuos pero a la vez los empuja a unos sobre otros, destruyendo el tejido de relaciones e interacciones y haciendo que la capacidad de actuar se haga cada vez más improbable. En este sentido, continúa el epílogo: se trata del terror como coacción total que ....presiona a las masas de hombres aislados $y$, las mantiene en un mundo que se ha convertido en un desierto para ellos (Arendt 2004, 574).

Por su parte, en términos del trabajo-labor, la sociedad de laborantes, cuya forma de producción basada en la división del trabajo y su consideración del trabajador-labor como 'fuerza de trabajo' tal como ya hemos visto en el apartado anterior, hacen del trabajador un ser intercambiable ${ }^{34}$ que cumple una función no especializada en la cadena productiva, y que funciona como una tuerca reemplazable por otra igual en el engranaje mayor del sistema productivo ${ }^{35}$. En este sentido, la sociedad de laborantes es también una sociedad de individuos aislados o, más bien, de cuerpos separados y dispuestos en un movimiento laborante, para el mantenimiento de su propio proceso vital (Arendt 1993, 166). Como dice Arendt en el segundo libro de The Origins of Totalitarianism (Imperialism), el hombre-masa es el ser aislado por excelencia, desvinculado de las relaciones sociales (Arendt 2004, 398), pero también de sí mismo, de la posibilidad de mostrar su propia diferencia, de mostrar unicidad. Se trata de hombres masa que no están integrados y son más bien "puro número", seres indiferenciados que no tienen la posibilidad de reconocer organización ni interés común (Arendt 2004, 392).

Pero según el epílogo, el totalitarismo procura no solo el aislamiento sino también la soledad; allí radicaría al menos parte de su verdadera novedad. Se trata no

34 “...la producción masiva sería imposible sin reemplazar a los trabajadores y a la especialización por laborantes y la división de la labor" (Arendt 1993,134).

35 La imagen de la tuerca en el engranaje recuerda sin duda a la figura de Eichmann que explica su propio lugar en el sistema de la Solución Final, utilizando esta imagen. Ver especialmente "Personal Responsability Under Dictadorship" y "Collective Responsability", en Arendt 2003. 
solo de atomizar a los individuos y desvincularlos de los demás haciendo desaparecer el espacio entre ellos, sino también de atacar y destruir la esfera privada (Arendt 2004, 576). Lo que resulta destruido con la soledad es la última frontera de la identidad, lo que en el primer apartado hemos llamado pérdida de la espontaneidad del individuo (Arendt 2004, 576).

Pero esta soledad, no es nueva en el mundo moderno. En este sentido nos advierte:

Lo que prepara a los hombres para la dominación totalitaria en el mundo no totalitario es el hecho de que la soledad, antaño una experiencia liminal habitualmente sufrida en condiciones sociales marginales como la vejez, se ha convertido en una experiencia cotidiana de crecientes masas de nuestro siglo. El proceso implacable por el que el totalitarismo impulsa y organiza a las masas parece como un escape suicida a esta realidad (Arendt 2004, 578). Esta soledad que Arendt describe como soledad de las masas surge de la mano de una forma de entender el trabajo y la producción que ha destruido el quehacer del homo faber que, aunque aislado nunca estuvo solo. En este sentido nos advierte la autora: El hombre en cuanto homo faber tiende a aislarse de su obra, es decir, a abandonar temporalmente el terreno de la política. La fabricación (poiesis, la elaboración de cosas), como diferenciada de la acción (praxis), por otra parte, $y$ de la pura labor ${ }^{36}$, por otra, es realizada siempre en un cierto aislamiento de las preocupaciones comunes (...). Sin embargo, en el aislamiento, el hombre permanece en contacto con el mundo como artifice humano; solo cuando es destruida la más elemental forma de creatividad humana, que es la capacidad de añadir algo propio al mundo común, el aislamiento se torna inmediatamente insoportable. Esto puede suceder en un mundo cuyos principales valores sean dictados por la labor ${ }^{37}$, es decir, donde todas las actividades humanas hayan sido transformadas en labor ${ }^{38}$. (...)El hombre aislado, que ha perdido su lugar en el terreno político de la acción, es abandonado también por el mundo. Ya no es reconocido como un homo faber, sino tratado como un animal laborans cuyo necesario "metabolismo con la Naturaleza” no preocupa a nadie (...). Entonces el aislamiento, se vuelve soledad (Arendt 2004, 575).

La soledad surge entonces cuando se han cortado los vínculos no solo con los otros seres humanos y consigo mismo como el hombre masa, sino finalmente con el mundo, como horizonte que hace posible el arraigo y la permanencia, como espacio de comprensión que da significado a las empresas prácticas productivas y políticas. El mundo y nuestra instalación en él es lo que la soledad provocada por la sociedad del trabajo-labor y la soledad construida controladamente por la sociedad de los campos de concentración ponen en entredicho. Instalación en el mundo que el homo faber suponía, mantenía, y alimentaba, ya que poblaba de objetos al mundo.

36

En la edición castellana utilizan 'trabajo', pero en el original ingles dice 'labor'. Atendiendo a la importante distinción entre 'labor' y 'work' que la traducción no respeta, traducimos como 'labor'. Ver original inglés: Arendt 1994a, 475.

37

38 
Arendt nos aclara: Estar desarraigado significa no tener en el mundo un lugar reconocido y garantizado por lo demás; ser superfluo significa no pertenecer en absoluto al mundo. El desarraigamiento puede ser la condición preliminar de la superfluidad (Arendt 2004, 576).

Desarraigo y superfluidad son fenómenos vinculados que se abren paso en la modernidad, sobre todo a partir del trabajo-labor y de consumo, para cristalizar en su forma más extrema en los sistemas del terror totalitario. Lo interesante para nosotros es que sociedad del trabajo-labor y sociedad basada en el terror buscan 'convertir a los hombres en seres superfluos' y la coincidencia en este objetivo resulta a los ojos de Arendt completamente explícita: La soledad, el terreno propio del terror, la esencia del Gobierno Totalitario, y para la ideología o la lógica, la preparación de ejecutores y víctimas, está estrechamente relacionada con el desarraigamiento y la superfluidad, que han sido el azote de las masas modernas desde el comienzo de la revolución industrial y que se agudizaron con el auge del imperialismo a finales del siglo pasado y la ruptura de las instituciones politicas y las tradiciones sociales en nuestro propio tiempo (Arendt 2004, 576) ). $^{39}$.

Los campos de concentración que culminan este proceso mediante el cual el hombre masa se hace completamente superfluo, un muerto-vivo o ser inanimado, son en realidad fábricas controladas y planificadas para la generación de esta superfluidad. Pero la experiencia misma de esta superfluidad, vuelve a insistir Arendt, no es en ningún sentido nueva, ya está instalada en la experiencia de las modernas masas: El intento totalitario de hacer superfluos a los hombres refleja la experiencia que las masas modernas tienen de su superficialidad en una Tierra superpoblada. El mundo de moribundos, en el que se enseña a los hombres que son superfluos a través de un estilo de vida en el que se practica la explotación sin beneficio y donde se realiza el trabajo sin producto, es un lugar donde diariamente se fabrica el absurdo (Arendt 2004, 554). Se trata de un largo aprendizaje de este absurdo, del "trabajo sin producto", de la "explotación sin beneficio" y de un "estilo de vida" que han terminado vaciando de sentido la actividad humana práctica, mediante un proceso que ha durado siglos y cuya pieza central es la implantación de un noción de trabajo-labor, un sistema productivo y una sociedad en torno a ello.

En este sentido, puede verse con claridad que la concreta experiencia de trabajolabor moderno, como experiencia práctica que gobierna el mundo desde la revolución industrial, no solo es condición previa del proceso de hacer a los hombres superfluos que ocurre en los campos, sino que es ella misma parte fundamental del lento proceso de superfluidad que es la misma cultura moderna, como forma de distanciación de lo práctico mediada por un trabajo-laborizado, como actividad sin sentido, cíclica, abstracta, desvinculada del propio trabajador, en el que ya no importa el producto, ni el mundo, ni los otros, sino el mantenimiento de una superproducción para la sobrevivencia y la expansión de un ritmo de consumo, ahora a escala planetaria. 
Según nos muestra el epílogo que hemos revisado en este apartado, es la moderna sociedad de trabajo-labor la que prefigurará una sociedad de nuevos esclavos modernos. El animal laborans será este nuevo esclavo doméstico (Arendt 1993, 128) que sobrevive para trabajar y trabaja para sobrevivir. El individuo moderno y su ilusorio poder transformador, en medio de un sistema que no avanza ni transforma sus condiciones, sino que muy por el contrario, repite cíclicamente un proceso que profundiza en sus amarras las condiciones de su dependencia, soledad y esclavitud. Haciendo retroceder las capacidades de arraigo y creación del mundo que hacía posible el 'trabajo' (work) en su sentido originario. Se trata de un ser práctico, trabajador-laborante, completamente preparado para el funcionamiento eficiente pero sin libertad, habilitado para las sobrevivencia extrema pero sin espontaneidad, ejercitado en su adaptación a un esquema de dominación (Arendt 2004,554), y ya en pleno proceso de convertirse en un ser superfluo, que consiste finalmente, y como hemos intentado mostrar, en la desmundanización de nuestra experiencia: la pérdida de nuestra relación con el mundo, como pérdida de las coordenadas existenciales, pero también práctico-políticas, creativoproductivas que nos ligan e instalan en ese mundo. Cuestiones que cristalizan en el acosmismo de la experiencia humana moderna y contemporánea (Tassin 1999, 209).

Es así posible pensar en una identificación al menos parcial entre interno del campo y animal laborans de la moderna sociedad de masas. Ambos están imbuidos en la tarea de la mera sobrevivencia y están atrapados en el tiempo cíclico que es el tiempo de esta sobrevivencia. Ambos son animales solitarios, lo que quiere decir, sin las posibilidades que abre el pensamiento y la producción (el trabajo en su sentido original para Arendt), sin mundo y sin un espacio donde la propia intimidad, la experiencia del sí mismos y de la comunicación con otros sea posible.

Lo importante para nosotros es que el trabajo-labor moderno organiza nuestro mundo de manera tal que hace del campo de concentración su propia posibilidad, última y extrema por lo demás. De la misma manera en que en sentido inverso, la experiencia de los campos realiza bajo la forma de su parodia llevada al absurdo, la cotidianeidad del laborante.

En este sentido, incluso después de que los totalitarismos han caído, al menos los que reconocemos bajo su forma clásica, permanecen los puentes comunicantes entre terror, labor y consumo, y conforman no solo el tránsito entre The Origins of Totalitarianism y The Human Condition, sino también la posibilidad de repensar las relaciones entre terror y sociedades postotalitarias de masas, en tanto sociedades que han sido adiestradas en la labor y el consumo. Cuestión que a nuestro juicio sigue siendo una vía de circulación y actualidad del pensamiento de Arendt.

Al mismo tiempo, es esta relación la que resulta especialmente iluminadora si nos situamos en un país como Chile. Teniendo a la vista la historia política y social reciente de este nuestro país: en la que la dictadura ${ }^{40}$, que puede ser pensada como una

40 Para una discusión acerca de los rasgos totalitarios y los no totalitarios de las dictaduras latinoamericanas, ver García de la Huerta 2008, 58 y ss. 
variante de régimen basado en el terror, está históricamente ligada a la implantación de un régimen social y económico que, en el sentido de Arendt, puede ser pensado como un régimen de labor y consumo. Pero estas relaciones particulares entre terror labor y consumo en el Chile de la dictadura y la post-dictadura constituyen tema de un trabajo sin duda distinto, que solo queda sugerido como camino posible y ulterior.

\section{Referencias bibliográficas}

Amiel, Anne (2000), Hannah Arendt. Política y acontecimiento. Buenos Aires: Nueva Visión.

Arendt, Hannah (2004), Los Orígenes del Totalitarismo (trad. cast.). Madrid: Taurus. (1994a), The Origins of Totalitarianism. New York: Harcourt. (1994b), Eichmann in Jerusalem: A Report on the Banality of Evil. New York: Penguin Books. (1993), La condicion humana (trad. Cast.). Barcelona: Paidós. (1998), The Human Condition. Chicago: Chicago University Press. (2003), (J. Kohn, ed.) Responsibility and Judgment. New York: Schocken. (2005), Ensayos de Comprensión: 1930-1954. Madrid: Caparrós.

(2006), Between Past and Future, Eight exercises in political thought. New York: Viking Press.

Arendt, Hannah y Mary Mc Carthy (1999), Entre amigas: Correspondencia 1949_ 1975. Barcelona: Lumen.

Bernstein, Richard (2002), Radical Evil. A Philosophical Interrogation.

Canovan, Margaret (1992), Hannah Arendt. A Reinterpretarion of Her Political Thought. Cambridge: Cambridge University Press.

Forti, Simona (2001), Il totalitarismo. Guis: Laterza \& Figli.

García de la Huerta, Marcos (2008), "Totalitarismo y dictadura", en Nitschack y Vatter (eds.), Hannah Arendt: sobrevivir al totalitarismo. Santiago: Lom.

Habermas, Jürgen (1984), Perfiles Filosóficos. Madrid: Taurus.

Henry, Michel (2011), Marx. Vol I; Una filosofia de la realidad (trad. cast.) Buenos Aires: La Cebra.

Hill, Michael (1979), Hannah Arendt, the recovery of the public world. New York: St. Martin Press.

Holman, C. (2011), "Reconsidering Hannah Arendt's Reading of Marx". CPSA Presentation. Departament of York University. http://www.cpsa-acsp.ca/ papers-2011/holman.pdf .

López, Maria José (2010), “Arendt y la 'historia salvaje': la política y la historia que no se pueden fabricar", Revista Isegoría, $\mathrm{n}^{\circ} 43$, junio - diciembre, pp. 643-658.

Marcuse, Herbert (2010), El hombre unidimensional. Madrid: Editorial Ariel. 
Marx, Karl (2000), Manuscritos económico-filosóficos de 1844. Buenos Aires: Editorial Colihue. (2011), El Capital. Santiago de Chile: Lom.

Negri, Antonio y Hardt, Michel (2002), Imperio. Barcelona: Paidós.

Pitkin, Hannah (1998), The Attack of the Blob: Hannah Arendt's concept of the social. Chicago: Chicago University Press.

Ring, J. (1989), “On Needing Both Marx and Arendt: Alienation and the Flight from Inwardness”, Political Theory, vol. 17, núm. 3, págs. 432-448.

Sánchez, Cristina (2003), Hannah Arendt El sentido de lo político. Madrid: Centro de Estudios Constitucionales.

Schutting, W.A. (1962), “Marx and Hannah Arendt's The Human Condition”, Ethics, Vol. 73, No. 1 (Oct.), pp. 47-55.

Tassin, Etienne (1999), Le trésor perdu. Paris: Editons Payot.

Villa Dana (1999), Politics, philosophy, terror, essays on the thought of H. Arendt. Princeton: Princeton University Press.

Young-Bruhel, Elizabeth (1993), Hannah Arendt, el amor del mundo. Valencia: Edicions Alfons el Magnànim. 